\title{
Early growth and markers of cardiovascular risk in Keralan children in the Integrated Child Development Scheme
}

\author{
Nick Brown ${ }^{1, *}$, Chaniyil Krishnan Sasidharan ${ }^{2}$ and David Fisher ${ }^{3}$ \\ ${ }^{1}$ Salisbury District Hospital, Salisbury, Wiltshire, SP2 8BJ, UK: ${ }^{2}$ Baby Memorial Hospital, Khozikode, Kerala, \\ India: ${ }^{3}$ Medical Research Council, Clinical Trials Unit, London, UK
}

Submitted 4 November 2008: Accepted 7 August 2009: First published online 22 September 2009

\begin{abstract}
Objective: Low birth weight is associated with increased lifelong morbidity. Kerala has a renowned, low-cost, maternal-child health system in which is couched universal access to the Integrated Child Development Scheme (ICDS), central to which is community-based maternal-infant nutritional supplementation. We assessed whether children in this environment showed enhanced birth weight and postnatal growth and whether the evolution of early markers of CVD was attenuated in comparison to contemporaries from other states.

Design: A part retrospective, part prospective cohort study in which children ( $n$ 286) born in 1998-2000 in Calicut were identified from Anganwadi records. They were traced at 6 years and underwent full anthropometry and blood pressure measurements at 6 and 8 years.

Results: Mean birth weight $(2 \cdot 86$ (SD $0 \cdot 40) \mathrm{kg}$ ) was greater than in Indian contemporaries but consistently $<-1 \mathrm{SD}$ below the National Center for Health Statistics reference median throughout childhood. Birth weight significantly predicted body mass (BMI) at 8 years. Lower birth weight was strongly predictive of a higher waist:hip ratio (WHR) indicative of adverse central (coelomic) fat distribution $(P<0 \cdot 01)$. Faster weight gain in infancy was weakly predictive of a lower WHR $(P=0.59)$, but faster late childhood growth at 6-8 years was nonsignificantly predictive of adverse WHR.

Conclusions: At 8 years of age, children in Calicut participating in the ICDS have greater birth weight and relative attenuation of the evolution of early CVD markers compared with children in apparently comparable states. The relative contributions of the ICDS and other factors inherent to Kerala cannot be inferred from the present study.
\end{abstract}

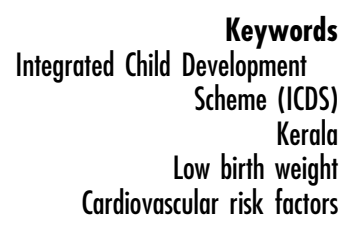

The association between low birth weight and adult chronic disease was first reported over 20 years ago. Since then, the same inference has been made in cohort studies worldwide. These have consistently shown a higher prevalence of CVD markers, glucose intolerance, immunological impairment and cognitive deficiencies in adults born with low birth weight relative to their contemporaries with 'appropriate' birth weight. The causal pathway is complex. Birth weight is a 'marker' of maternal-fetal nutrition, placental function, gene and gene/ nutrient expression, and intra-uterine infection load. Postnatal growth and nutrition are further major effect modifiers ${ }^{(1-4)}$. In India, studies have provided evidence of additional postnatal interactions of low birth weight with both maternal and children's diet and activity levels ${ }^{(2-4)}$.

The state of Kerala, despite a low per capita income, has long held a reputation for its health indices, suggesting that evidence-based use of available resources rather than major investment is the key. The Integrated
Child Development Scheme (ICDS) was launched in 1977 in thirty-three centres on a national level and focused on families belonging to the lower socio-economic strata with an aim of improving the health, nutrition and development of children. Central to the scheme is the provision of a cereal-based meal providing approximately $2 \mathrm{MJ} / 25 \mathrm{~g}$ protein and $1 \cdot 25 \mathrm{MJ} / 10 \mathrm{~g}$ protein daily to pregnant and lactating women and children under 6 years old, respectively. The supplementation programme is augmented by basic health and hygiene education, anaemia control and immunisation. Coverage in Kerala is nearuniversal, though is of the order of $50 \%$ of the total population of children elsewhere in $\operatorname{India}^{(5-7)}$.

The ICDS is administered in population blocks of 100000 , further sub-divided into small units of 1000 which are referred to as Anganwadi (kindergarten) areas. Each such area is managed by a matriculate female community health worker and a female helper from the same locality. Funding for the scheme is provided by the 
Departments of Social Welfare and Health and the Anganwadi centres are provided by the community.

In Calicut, the supplement consists of a nutritional mix called amritham, a mix of wheat, green gram and oil. It is available (on collection) to pregnant and lactating mothers, adolescent girls and children less than 6 years of age. Additionally the scheme supplies Fe and folic acid for mothers and adolescent girls, and child growth monitoring, immunisation and non-formal pre-school education.

Calicut ICDS Project Urban 1 was initiated in 1977 and is administratively divided into four sectors demarcated by natural boundaries. In 2000 the total population under 6 years of age was 1213 . The area is largely Muslim and $75 \%$ of the adult male population is employed as labourers or in the offshore fishing industry.

We sought to test the hypothesis that, with universally affordable health service and ICDS coverage, the children of Kerala would enjoy more favourable growth patterns than other Indian children and that early susceptibility to chronic disease might be attenuated.

\section{Methods}

The study was approved by the Department of Social Welfare, Kerala State Government. The children were traced from the Angawadi register with the help of the Angawadi workers at the age of 6 years (2003-4) and their families contacted. We obtained informed consent from all families and the children were brought for clinical assessment. Initial measurements were done at the age of 6 years (as close to the 6th birthday as feasible) and repeated two years later at the age of 8 years. Two of the authors (N.B. and C.K.S.) trained and supervised a team of medical students all of whom underwent both baseline intra-observer testing and repeat testing a year later to ensure reliability. The following measurements were made at each visit: (i) weight (standing) taken on Seca electronic scales; (ii) blood pressure by means of an Omeron electronic BP apparatus; and (iii) skinfold thickness measurement by callipers (each measure made three times). Data were double-entered and cleaned as necessary. We identified the following as outcomes of potential cardiovascular importance and analysed them as dependent variables: (i) blood pressure; (ii) waist: hip ratio (WHR); and (iii) subscapular:triceps skinfold ratio (SSTR). Both WHR and SSTR are established markers of central (coelomic) fat deposition, a phenotype to which the Indian population appears particularly susceptible ${ }^{(8,9)}$. High WHR and SSTR suggest greater central adiposity; conversely, obesity with low WHR and SSTR, i.e. more general fat deposition, has lower associated risk.

\section{Statistical methods}

All data were double-entered. The lack of resources limited the verification of accuracy and consistency during data collection, so we generated histograms of all variables to be examined by eye. Anomalous values were flagged up, as were inconsistencies (e.g. a later weight being less than a previous weight for the same subject; negative values for age). Two of us (D.F. and N.B.) reviewed these values and where possible corrected them to their nearest accurate values (e.g. factors of 10). If the correct value was not obvious or could not be decided upon, it was set to missing - no interpolation was carried out.

We calculated external $Z$-scores for weight-for-age by the least-mean squares method, using the 2006 WHO reference data ${ }^{(10)}$.

Skinfold measurements were taken three times; as the distributions were skewed, geometric means were taken in preference to arithmetic means. We log-transformed the measurements of skinfold and standardised them to have zero mean and unit standard deviation in order to aid interpretation for regression analyses.

We adjusted growth data and 8-year outcome measurements to a constant age at each time point (e.g. all 2-year measurements were adjusted to age exactly 2 years), and to male sex. In addition, we performed the regression of growth data at each time point $v$. data from all previous time points to create residuals interpretable as conditional weights. The regressions themselves were univariate (as adjustments for age and sex had already been made).

All statistical analyses were carried out using the STATA statistical software package version 9 (Stat Corp., College Station, TX, USA).

\section{Results}

During the study period, 286 babies with birth weight data were followed up (Tables 1 and 2). Of these we collected complete follow-up data on 210 children $(73 \cdot 4 \%)$ and partial data were available on $241(84 \cdot 3 \%)$ at 8 years of age. Mean birth weight was $2 \cdot 86(\mathrm{sD} 0 \cdot 40) \mathrm{kg}$. The infants remained light by international (National Center for Health Statistics, NCHS) norms, with weight remaining $<-1 \mathrm{sD}$ below the reference median from 6 months onwards, the nadir being at 6 months.

A higher birth weight was found to significantly predict a lower WHR $(P<0 \cdot 01)$ and greater BMI $(P<0 \cdot 05)$ at 8 years (Table 3). Additionally, a greater weight at 8 years (nonconditional) significantly predicted a lower WHR $(P<0 \cdot 05)$.

Faster weight gain in infancy was weakly predictive of lower WHR and SSTR $(P=0 \cdot 59)$. Faster late childhood growth at 6-8 years was non-significantly predictive of higher WHR.

The associations between weight, growth and blood pressure were all non-significant (Tables 3 and 4, Fig. 1). There was no significant association between birth weight and 8-year systolic blood pressure. A greater weight score at any age was associated with an increase in systolic blood pressure, but conditional adjustment for previous weights attenuated the coefficients to non-significance. 
Table 1 Weight and weight-for-age Z-score at different time points among children ( $n$ 286) born in 1998-2000 and participating in the Integrated Child Development Scheme, Kerala, India

\begin{tabular}{|c|c|c|c|c|c|c|c|c|}
\hline \multirow[b]{2}{*}{ Time point } & \multicolumn{3}{|c|}{ Age at measurement (years) } & \multicolumn{3}{|c|}{ Weight (kg) } & \multicolumn{2}{|c|}{ Weight-for-age Z-score* } \\
\hline & $n$ & Median & IQR & $n$ & Mean & SD & Mean & SD \\
\hline Birth & & & & 286 & $2 \cdot 86$ & 0.40 & -0.98 & 0.96 \\
\hline 6 months & 265 & 0.50 & $0.46,0.51$ & 269 & $6 \cdot 10$ & 0.93 & $-1 \cdot 92$ & $1 \cdot 37$ \\
\hline 12 months & 284 & $1 \cdot 00$ & $0.97,1.01$ & 284 & $8 \cdot 03$ & $1 \cdot 06$ & $-1 \cdot 31$ & $1 \cdot 12$ \\
\hline 18 months & 281 & $1 \cdot 49$ & $1 \cdot 46,1 \cdot 51$ & 283 & $9 \cdot 14$ & $1 \cdot 11$ & $-1 \cdot 31$ & $1 \cdot 04$ \\
\hline 2 years & 282 & $2 \cdot 00$ & $1 \cdot 96,2 \cdot 01$ & 282 & $10 \cdot 16$ & $1 \cdot 20$ & $-1 \cdot 32$ & $1 \cdot 00$ \\
\hline 4 years & 253 & 3.99 & $3 \cdot 96,4 \cdot 01$ & 252 & $13 \cdot 39$ & $1 \cdot 28$ & $-1 \cdot 50$ & 0.75 \\
\hline 6 years & 287 & $5 \cdot 49$ & $4 \cdot 73,6 \cdot 17$ & 285 & $15 \cdot 68$ & $2 \cdot 37$ & $-1 \cdot 57$ & 0.97 \\
\hline 8 years & 241 & $7 \cdot 38$ & $6 \cdot 64,8 \cdot 19$ & 210 & $19 \cdot 30$ & $3 \cdot 11$ & $-1 \cdot 52$ & $1 \cdot 04$ \\
\hline
\end{tabular}

IQR, interquartile range.

*Using 2006 WHO data ${ }^{(10)}$.

Table 2 Growth outcomes at 8-year follow-up among children ( $n$ 286) born in 1998-2000 and participating in the Integrated Child Development Scheme, Kerala, India

\begin{tabular}{lccc}
\hline Variable & $n$ & $\%$ & \\
\hline Male sex & 140 & $48 \cdot 8$ & \\
& $n$ & Mean & SD \\
\cline { 2 - 4 } Height (cm) & 211 & $116 \cdot 8$ & $6 \cdot 95$ \\
MUAC (cm) & 212 & $16 \cdot 2$ & $1 \cdot 45$ \\
Head circumference (cm) & 212 & $49 \cdot 9$ & $1 \cdot 70$ \\
BMI (kg/m $\left.{ }^{2}\right)$ & 210 & $14 \cdot 1$ & $1 \cdot 46$ \\
WHR (\%) & 211 & $88 \cdot 6$ & $4 \cdot 48$ \\
& $n$ & Median & IQR \\
\cline { 2 - 4 } SSTR (\%) & 211 & $79 \cdot 9$ & $71 \cdot 1,88 \cdot 8$ \\
Triceps skinfold (mm) & 211 & $6 \cdot 86$ & $5 \cdot 87,8 \cdot 00$ \\
Biceps skinfold (mm) & 211 & $4 \cdot 33$ & $3 \cdot 73,5 \cdot 13$ \\
Subscapular skinfold (mm) & 211 & $5 \cdot 27$ & $4 \cdot 67,6 \cdot 20$ \\
Suprailiac skinfold (mm) & 211 & $5 \cdot 80$ & $4 \cdot 87,7 \cdot 66$ \\
\hline
\end{tabular}

MUAC, mid upper-arm circumference; WHR, waist:hip ratio; SSTR, subscapular:triceps skinfold ratio; IQR, interquartile range.

\section{Discussion}

The children in our cohort were of greater birth weight than contemporaries born in non-ICDS areas such as rural Maharashtra $(2 \cdot 66 \mathrm{~kg})$, urban Andhra Pradesh (Hyderabad; $2.59 \mathrm{~kg})$ and rural Andhra Pradesh $(2 \cdot 50 \mathrm{~kg})^{(11-13)}$. However, during infancy and early childhood the children's weight remained consistently more than 1sD below the NCHS reference median with a nadir weight-for-age $Z$-score at 6 months of age.

The birth weight predicted higher BMI and a lower WHR at 8 years; thus a larger baby would be likely to remain large but appropriately so, with the weight gain in the form of 'healthier' lean tissue or peripheral adipose tissue rather than central/coelomic fat. Although not necessarily of importance at this age, this suggests (assuming this trajectory were to continue) that heavier babies are afforded protection against CVD with signs identifiable by mid-childhood.

Put another way, the trajectory of a lower-birth-weight baby would be towards a lower BMI and more adverse, centrally adipose phenotype at 8 years of age, a finding comparable to those from other studies ${ }^{(12-17)}$.
Unlike in other cohorts, low birth weight appeared to have no significant association with blood pressure in the present study. Whether this is a result of intra-uterine protection, more favourable growth trajectories, local nutritional factors or other (genetic) factors inherent to Keralan children cannot be inferred at this stage.

The timing of postpartum growth was important and seemed to be an additional effect modifier. Rapid infant growth appeared protective, but rapid later childhood growth (between 6 and 8 years of age) weakly predicted adverse WHR and systolic blood pressure. These trajectories have been identified in other studies ${ }^{(12-20)}$. Those in the lowest birth weight tertile remained at higher risk of a high WHR but this was attenuated by faster overall growth. These findings are compatible with the Barker hypothesis $^{(1)}$, in which suboptimal intra-uterine growth modified by further 'adverse' post-infant growth triggers a susceptibility to potentially harmful patterns of fat deposition and other risk factors for chronic disease.

How then do we interpret these findings? The inference appears to be that our cohort shows some similarity in risk profiles to other Indian children but with a degree of attenuation. The explanation for the latter is likely to be complex, as discussed in the following.

Supportive recent evidence from Andhra Pradesh suggests that adults in their third decade who benefited from the ICDS scheme as children have fewer risk factors of CVD and impaired glucose tolerance than contemporaries originally from adjacent areas where ICDS was instituted later $^{(12)}$. In the Kerala ICDS, pregnant women and their children receive of the order of an additional 15-20\% of energy above the 'norm'. It is likely that this is at least a partial explanation for the greater birth weights and that these children, postnatally, are metabolically more 'resilient' as a result. Indeed, our results do show less pronounced changes in adverse anthropometry and blood pressure for given growth patterns.

What then of other explanations for our findings and the implications for generalisability? Can the Kerala model be replicated?

Despite a low per capita income, Kerala has had outstanding key health outcomes such as perinatal mortality, 
Table 3 Regressions of weight $v$. blood pressure and fat distribution among children ( $n$ 286) born in 1998-2000 and participating in the Integrated Child Development Scheme, Kerala, India

\begin{tabular}{|c|c|c|c|c|c|c|c|c|c|c|}
\hline & \multicolumn{10}{|c|}{ Outcomes at 8-year follow-up } \\
\hline & \multicolumn{2}{|c|}{ Systolic blood pressure $(\mathrm{mmHg})$} & \multicolumn{2}{|c|}{ Diastolic blood pressure $(\mathrm{mmHg})$} & \multicolumn{2}{|c|}{ SSTR (SD of log) } & \multicolumn{2}{|c|}{ BMI $\left(\mathrm{kg} / \mathrm{m}^{2}\right)$} & \multicolumn{2}{|c|}{ WHR (\%) } \\
\hline & Coefficient & SE & Coefficient & SE & Coefficient & SE & Coefficient & SE & Coefficient & SE \\
\hline \multicolumn{11}{|c|}{ Birth weight (raw data; $\mathrm{kg}$ ) } \\
\hline Birth & $1 \cdot 452$ & $1 \cdot 810$ & $2 \cdot 222$ & $1 \cdot 559$ & 0.009 & $0 \cdot 175$ & $0 \cdot 612^{*}$ & $0 \cdot 251$ & $-2 \cdot 066^{\star *}$ & 0.729 \\
\hline \multicolumn{11}{|c|}{ Adjusted weight $(\mathrm{kg})$} \\
\hline 6 months & $0 \cdot 183$ & $0 \cdot 774$ & 0.242 & 0.659 & -0.001 & 0.076 & $0 \cdot 254^{*}$ & $0 \cdot 110$ & $-0.990^{\star *}$ & 0.314 \\
\hline 12 months & 0.611 & 0.674 & 0.335 & 0.582 & -0.023 & 0.065 & $0 \cdot 516^{* \star *}$ & 0.088 & $-0.913^{\star *}$ & $0.26 \mathrm{~s}$ \\
\hline 18 months & 0.490 & 0.681 & 0.344 & 0.588 & 0.015 & 0.066 & $0.637^{\star \star \star}$ & 0.085 & $-0.764^{\star \star}$ & 0.275 \\
\hline 2 years & 0.383 & $0 \cdot 610$ & 0.327 & 0.526 & -0.020 & 0.059 & $0.595^{\star \star \star}$ & 0.076 & -0.484 & $0.24 \varepsilon$ \\
\hline 4 years & 0.323 & 0.592 & 0.493 & 0.505 & -0.073 & 0.058 & $0.540^{\star * *}$ & 0.072 & $-0.514^{*}$ & 0.238 \\
\hline 6 years & 0.698 & 0.360 & 0.483 & 0.312 & 0.000 & 0.035 & $0.437^{\star \star *}$ & 0.042 & $-0.479^{\star *}$ & 0.146 \\
\hline 8 years & $0.572^{*}$ & 0.259 & 0.373 & $0 \cdot 225$ & -0.001 & 0.025 & $0 \cdot 390^{\star \star \star}$ & 0.025 & $-0 \cdot 261^{\star}$ & $0 \cdot 107$ \\
\hline \multicolumn{11}{|c|}{ Conditional adjusted weight (residuals; kg) } \\
\hline 6 months & 0.031 & 0.795 & -0.058 & 0.678 & -0.002 & 0.078 & $0 \cdot 197$ & $0 \cdot 114$ & $-0 \cdot 807^{\star}$ & 0.326 \\
\hline 12 months & $0 \cdot 366$ & 0.948 & 0.007 & $0 \cdot 806$ & -0.058 & 0.092 & $0 \cdot 605^{\star \star \star}$ & $0 \cdot 127$ & -0.627 & 0.391 \\
\hline 18 months & 0.030 & $1 \cdot 180$ & $-0 \cdot 328$ & 1.005 & $0 \cdot 142$ & $0 \cdot 115$ & $0 \cdot 574^{\star \star \star}$ & $0 \cdot 162)$ & 0.052 & 0.490 \\
\hline 2 years & $0 \cdot 290$ & $1 \cdot 066$ & 0.503 & 0.907 & $-0 \cdot 108$ & $0 \cdot 104$ & $0 \cdot 392^{\star \star}$ & $0 \cdot 148$ & 0.227 & 0.442 \\
\hline 4 years & $0 \cdot 131$ & 0.926 & 0.046 & 0.775 & $-0 \cdot 127$ & 0.092 & $0 \cdot 359^{\star *}$ & $0 \cdot 126$ & -0.356 & $0.37 \varepsilon$ \\
\hline 6 years & $1 \cdot 031$ & 0.567 & 0.282 & 0.479 & 0.023 & 0.056 & $0 \cdot 388^{\star \star *}$ & 0.075 & $-0.562^{*}$ & 0.228 \\
\hline 8 years & 0.472 & 0.606 & -0.265 & 0.508 & 0.027 & 0.058 & $0.452^{\star \star \star}$ & 0.076 & $0 \cdot 102$ & 0.247 \\
\hline
\end{tabular}

SSTR, subscapular:triceps skinfold ratio; WHR, waist:hip ratio

Coefficient was statistically significant: ${ }^{*} P<0.05,{ }^{\star \star} P<0.01,{ }^{* \star *} P<0.001$. 
infant mortality and life expectancy for many years. In policy terms, Kerala, unlike other states, has had a long state-level commitment to public and social services; this includes education, with literacy rates far higher than elsewhere. These have been achieved despite a high migrant population and comparable levels of poverty to other states ${ }^{(21,22)}$.

Of great importance and direct benefit also are the other, non-nutritional components of the $\operatorname{ICDS}^{(6,7)}$ and Kerala health service. These include: universal access to antenatal care; hospital delivery; education and high literacy rates; and high vaccinations rates. Access to and usage of the family planning services ensures less intense nutritional demand on mothers and some financial protection for families.

There appears to be a degree of maternal, fetal and postnatal protection through the ICDS programme and the whole Kerala health and social programme. We were not able to measure genetic or lifestyle factors in this stage of the study but would be interested in assessing these over the coming years.

We acknowledge a number of weaknesses in the present study. Currently we only have data to the age of 8 years and we cannot extrapolate with any confidence to adulthood. We therefore feel a responsibility to continue follow-up in the long term. We had no direct control group as the ICDS programme in Calicut was accessible to everyone, but have a number of quasi controls from other (non-ICDS) areas of similar background. At birth the only data (albeit complete) available were birth weight; other anthropometric measures (including parental) were not available nor was gestation known. However, we have no reason to believe that the range of gestation was markedly different from any other Indian cohort and therefore it is reasonable to infer that these babies were relatively well grown. Parental anthropometry would additionally have been useful in terms of elucidating the causal pathway.

The history of maternal nutritional trials is surprisingly controversial, with the overall evidence for maternal protein-energy supplementation at community level still debated $^{(23,24)}$. Meta-analysis of isoenergetic proteinenergy supplementation trials suggests possible harm in terms of risk of small for gestational age and mean birth weight from protein-energy hyperalimentation during pregnancy ${ }^{(25)}$. However, these programmes and studies have involved supplementation way in excess of the population norms and have not tested more modest, perhaps more appropriate increases.

Although the effect size of different growth trajectories is small statistically in terms of the outcomes we measured, there are a number of more subtle but equally important societal benefits from optimising intra-uterine and postnatal growth. These have been meta-analysed and published by the Maternal and Child Undernutrition Group ${ }^{(26)}$ and are worth contextualising here.

Their analysis showed that enhanced nutrition was clearly associated with improved education and economic productivity, with improvement in birth weight 

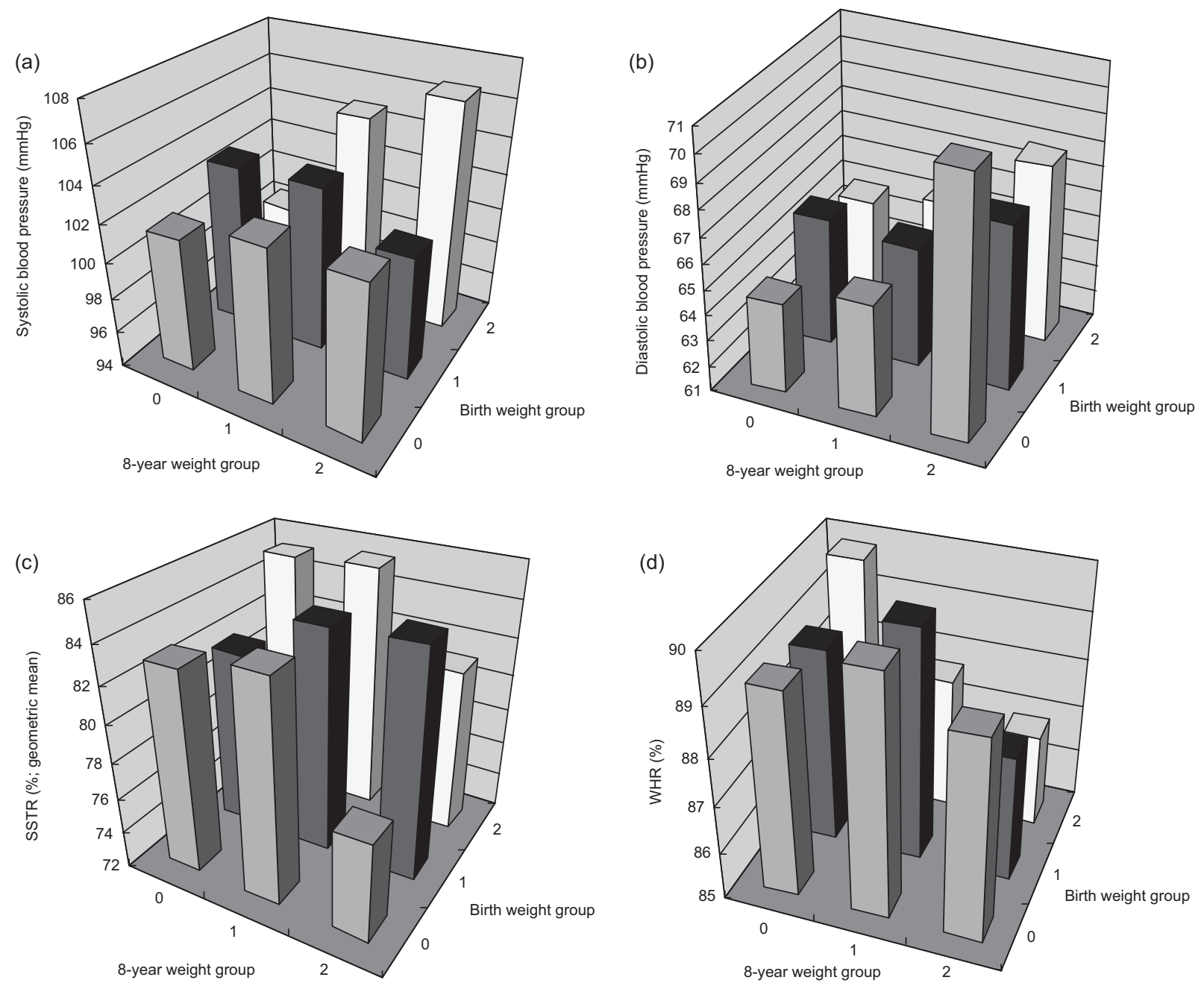

Fig. 1 Tertile plots of 8-year outcomes by weight at birth and at 8 years among children $(n 286)$ born in 1998-2000 and participating in the Integrated Child Development Scheme, Kerala, India: (a) systolic blood pressure $(P$ for interaction $=0 \cdot 194)$; (b) diastolic blood pressure $(P$ for interaction $=0.267)$; (c) subscapular:triceps skinfold ratio (SSTR; $P$ for interaction $=0.991$ ); (d) waist:hip ratio (WHR; $P$ for interaction $=0.095)$. $P$ values for interaction were calculated by ANOVA using continuous adjusted birth weight and 8-year weight data, to maximise the available power

in subsequent generations, so the benefits are enjoyed in future generations as well. In harder-to-quantify societal terms, a greater awareness of nutrition in health will generate a community momentum to improve nutrition.

At this stage our cohort is still too young to be confident that the encouraging findings can be extrapolated into adulthood. We aim to continue follow-up well beyond adolescence and hope to make additional measurements of markers of chronic disease in order to better inform future policy.

\section{Conclusions}

Children in Calicut within the ICDS scheme have greater birth weights than otherwise comparable infants in India. At the age of 8 years certain anthropometric trends are emerging. Birth weight predicts BMI and a lower WHR, suggesting a more favourable fat-free mass gain in larger babies. Faster infant growth appears weakly protective although rapid later growth is a non-significant risk factor of CVD. In summary, although these children have risk factor phenotypes comparable to other cohorts, they appear to be attenuated. The current study cannot assess the relative contributions of the ICDS and factors inherent to Kerala, but it seems likely there are a number of benefits of the state health system and the ICDS scheme that last beyond immediate infant morbidity and mortality. The integration of ICDS into the framework of the Kerala state commitment to social services illustrates what can be achieved in even the most resource-poor setting.

\section{Acknowledgements}

This research received no specific grant from any funding agency in the public, commercial or not-for-profit sectors. There are no conflicts of interest for any of the authors. 
N.B. was responsible for study design, training and write up. C.K.S. was the field supervisor and responsible for liaison. D.F. conducted the statistical analysis. The authors wish to thank the participating children and parents, the Anganwadis, the medical students who undertook the measurements and Dr Tina Tekkakkara for her helpful comments.

\section{References}

1. Barker DJP (1998) Mothers, Babies and Health in Later Life, 2nd ed. Edinburgh: Churchill Livingstone.

2. Barker DJ, Gluckman PD, Godfrey KM, Harding JE, Owens JA \& Robinson JS (1993) Fetal nutrition and cardiovascular disease in adult life. Lancet 341, 938-941.

3. Yajnik CS (2004) Early life origins of insulin resistance and type 2 diabetes in India and other countries. J Nutr 134, 205-210.

4. Bhargava SK, Sachdev HS, Fall CH, Osmond C, Lakshmy R, Barker DJ, Biswas SK, Ramji S, Prabhakaran D \& Reddy KS (2004) Relation of serial changes in childhood body-mass index to impaired glucose tolerance in young adulthood. $N$ Engl J Med 350, 865-875.

5. Kapil U \& Tandon BN (1990) ICDS scheme - current status, monitoring, research and evaluation system. Indian $J$ Public Health 34, 41-47.

6. Tandon BN (1989) Nutritional interventions through primary health care: impact of the ICDS projects in India. Bull World Health Organ 67, 77-80.

7. Patnaik S, Sarkar A, Sinha S \& Roy K (1999) Study of impact of nutrition and health strategy on the coverage rates of supplementary nutrition and health interventions among the ICDS beneficiaries in a rural block of Madhya Pradesh. Indian J Public Health 43, 32-36.

8. McKeigue PM, Shah B \& Marmot MG (1991) Relation of central obesity and insulin resistance with high diabetes prevalence and cardiovascular risk in South Asians. Lancet 337, 382-386.

9. Chowdhury B, Lantz H \& Sjostrom L (1996) Computed tomography-determined body composition in relation to cardiovascular risk factors in Indian and matched Swedish males. Metabolism 45, 634-644.

10. Multicentre Growth Reference Study Group (2006) WHO Child Growth Standards based on length/height, weight and age. Acta Paediatr Suppl 450, 76-85.

11. Rao S, Yajnik CS, Kanade A et al. (2001) Intake of micronutrient-rich foods in rural Indian mothers is associated with the size of their babies at birth: the Pune Maternal Nutrition Study. J Nutr 131, 1217-1224.

12. Kinra S, Rameshwar Sarma KV, Ghafoorunissa, Mendu VV, Ravikumar R, Mohan V, Wilkinson IB, Cockcroft JR, Davey Smith G \& Ben-Shlomo Y (2008) Effect of supplemental nutrition with public health programmes in pregnancy and early childhood on cardiovascular risk in Indian rural adolescents: long term follow-up of Hyderabad nutrition trial. BMJ 337, a605.

13. Bamji MS, VS Murthy PV, Williams L \& Vardhana Rao MV (2008) Maternal nutritional status and practices and perinatal, neonatal mortality in rural Andhra Pradesh, India. Indian J Med Res 127, 44-51.

14. Muthayya S, Dwarkanth P, Thomas T, Vaz M, Mhaskar A, Mhaskar R, Thomas A, Bhat S \& Kurpad A (2006) Anthropometry and body composition of south Indian babies at birth. Public Health Nutr 9, 896-903.

15. Joglekar CV, Fall CH, Deshpande VU et al. (2007) Newborn size, infant and childhood growth and body composition and cardiovascular disease risk factors at the age of 6 years: the Pune Maternal Nutrition Study. Int J Obes (Lond) 31, 1534-1544.

16. Fall CH, Sachdev HS, Osmond C et al. (2008) Adult metabolic syndrome and impaired glucose tolerance are associated with different patterns of body mass index gain during infancy: data from the New Delhi Birth Cohort. Diabetes Care 31, 2349-2356.

17. Sachdev HS, Fall CH, Osmond C, Lakshmy R, Dey Biswas SK, Leary SD, Reddy KS, Barker DJ \& Bhargava SK (2005) Anthropometric indicators of body composition in young adults: relation to size at birth and serial measurements of body mass index in childhood in the New Delhi birth cohort. Am J Clin Nutr 82, 456-466.

18. Singhal A, Wells J, Cole TJ, Fewtrall M \& Lucas A (2003) Programming of lean body mass: a link between birth weight, obesity and cardiovascular disease? Am J Clin Nutr 77, 726-730.

19. Gale CR, Martyn CN, Kellingray S, Eastell R \& Cooper C (2001) Intrauterine programming of adult body composition. J Clin Endocrinol Metab 86, 267-272.

20. Kipping RR, Jago R \& Lawlor DA (2008) Obesity in children. Part 1: Epidemiology, measurement, risk factors and screening. BMJ 337, 922-927.

21. Bhutta Z, Gupta I, de'Silva H, Manandhar D, Awasthi S, Hossain SM \& Salam MA (2004) Maternal and child health: is South Asia ready for change? BMJ 328, 816-819.

22. Srinivasan S \& Sukumar M (2006) Liberalisation and HIV in Kerala. Social Policy and Development Programme Paper no. 26. Geneva: United Nations Research Institute for Social Development.

23. Kusin JA, Kardjati S, Houtkooper JM \& Renqvist UH (1992) Energy supplementation during pregnancy and postnatal growth. Lancet 340, 623-626.

24. Adair LS \& Pollitt E (1985) Outcome of maternal nutritional supplementation: a comprehensive review of the Bacon Chow study. Am J Clin Nutr 41, 948-978.

25. Kramer MS \& Kakuma R (2003) Energy and protein intake in pregnancy. Cochrane Database Syst Rev issue 4, CD000032.

26. Victora CG, Adair L, Fall C, Hallal PC, Martorell R, Richter L \& Sachdev HS; Maternal and Child Undernutrition Study Group (2008) Maternal and child undernutrition: consequences for adult health and human capital. Lancet 371, 240-257. 